\title{
Epilogue
}

\author{
John Bennet
}

University of Sheffield

I am writing these words on a sheet of white paper, with a (cheap, disposable) fountain pen. By the time you read what I am writing, however, it will have been transformed. First, I will transfer it by a different set of bodily actions (typing on a keyboard) and through the software on my computer to convert it in to a string of $1 \mathrm{~s}$ and $0 \mathrm{~s}$. I will then send it through the ether to the editors who will, in turn, submit it in a similar digital form to the publisher. The publisher will use the digital file to produce a paper version, in essentially the same way that books have been produced for over 500 years, since the development of the printing press (in Europe) by Johannes Gutenberg. The chances are that you are now reading this in a form familiar for half a millennium, although you might well be viewing it on a digital device, again translated by that device's software into an arrangement of black and white pixels that mimics the printed page. Such are the processes of writing and reading in the second decade of the $21^{\text {st }}$ century...

\section{What is writing?}

The term 'writing' embodies two meanings - a process, involving the interaction of human bodies with materials normally mediated through various tools (pen, keyboard, etc.), and substance (cf. Piquette and Whitehouse, this volume), the material residues of those bodily actions on, or in, the surface of media of many kinds, permanent to varying degrees, even virtual, but visually legible, often tangible, at any time after writing has happened subject to preservation of the medium itself (cf. Cessford, this volume, on the range of media and their preservation in $18^{\text {th }}$ - to $20^{\text {th }}$-century Cambridge). For those of us who study writing in the past, the former is rarely visible (although writing or writers are sometimes represented visually and we occasionally recover writing tools; cf. e.g. Coe and Kerr 1997) and has to be deduced from the latter. In this respect, writing is like many other material products of the past: we have to reconstruct, or 'reverseengineer', the process of production, the chaine opératoire, from the artefacts themselves.

Writing, of course, implies a complementary, but distinct and sequential process of engagement with the product, a process that is visual and/or tactile and embodied and requires the

\section{How to cite this book chapter:}

Bennet, J. 2013. Epilogue. In: Piquette, K. E. and Whitehouse, R. D. (eds.) Writing as Material Practice: Substance, surface and medium. Pp. 335-342. London: Ubiquity Press. DOI: http:// dx.doi.org/10.5334/bai.q 


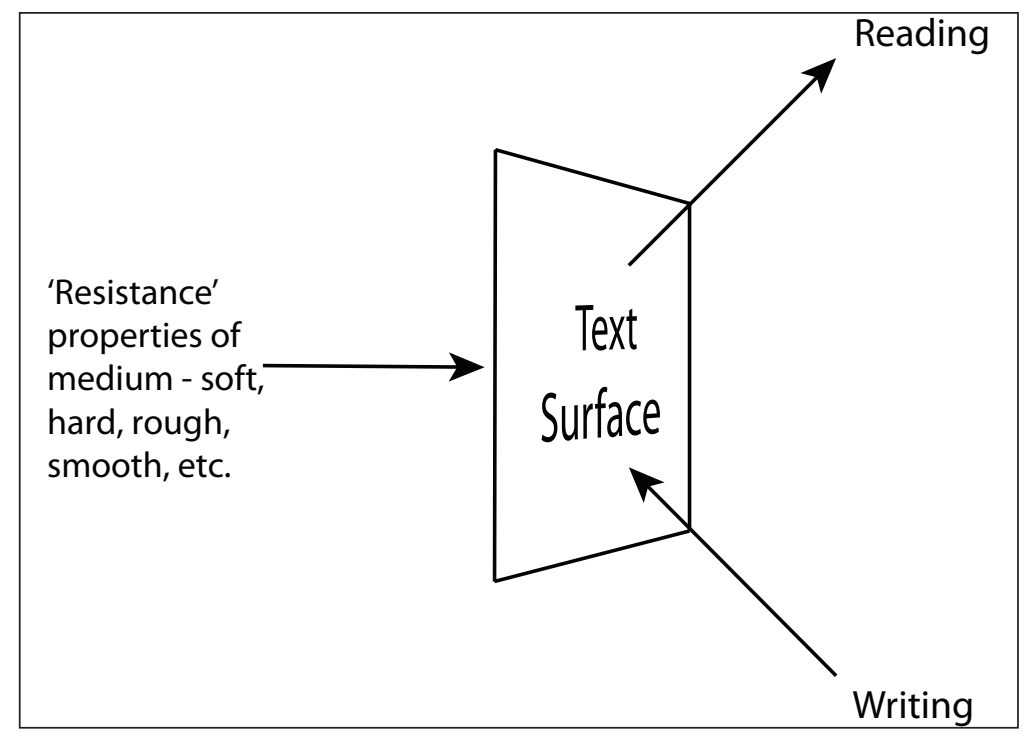

Figure 1: Diagram encapsulating concisely the processes associated with 'writing' and 'reading'.

presence of the material residues of writing. For the purposes of this epilogue, I loosely use the term 'reading' for this process, but suggest that 'reading' can potentially encapsulate a broader set of engagements than merely making sense of and absorbing a representation of language. Although this is perhaps clearest in contributions to this volume that explicitly deal with nonlanguage-based 'writing' (e.g. Salomon, on khipu; or Perego on 'iconic literacy'), it underpins the material-based approach that pervades the whole collection. The diagram in Figure 1 seeks to encapsulate concisely the processes associated with writing and reading. Because it is a material practice, writing requires a physical surface, on or into which it is applied, and requires bodily movements particular to different techniques for its production, the techniques dependent on the nature of the interaction between tool and medium. The process of writing might involve a single action - in the case, for example, of stamping or application of a transfer print ('indirect' forms of writing) - or multiple actions: flowing strokes (cf. Ingold 2007), where a brush or pen is used; staccato incisions or impressions, where a stylus is used on clay; repeated staccato actions, where a chisel is used on stone ('direct' forms of writing). The 'choreography' of writing - how the implement (brush, stylus) was held; how the surface was rotated, or not, to facilitate marking - was brought vividly home to those attending the original UCL Institute of Archaeology conference in demonstrations of Egyptian scripts written with a brush by professional scribe and calligrapher, Paul Antonio, and of cuneiform impressed into clay by British Museum Assistant Keeper of Cuneiform Collections, Jonathan Taylor. It also lies at the heart of Kidd's (this volume) exploration of the bilingual, bi-scriptural world of Ptolemaios, a late $3^{\text {rd }}$-century BCE 'Egyptian'.

Although it occupies a period of time, we can think of the 'moment of writing' (cf. Piquette, this volume) in contrast to the potentially multiple 'moments of reading' that might take place many times, minutes, days, even centuries or millennia afterwards, including the 'special case' of reading involving decipherment because knowledge of the original system has been lost. Depending on the portability of the material written upon, 'reading' may take place in the same location or at a distance; it may be achieved by the same actor, or a different one, or even be only an 'implied' reading aimed at supernatural beings. 'Reading', too, requires bodily movement: at a minimum, relatively small head, eye (e.g. Dehaene 2009: 12-18) and hand movements, but potentially quite extensive movements to appreciate writing laid out in (for us) unusual formats - an 'athletics of reading' (cf. Johnston; Whitehouse, both this volume). 
But this material process is not unique to writing. Because writing as a product is a visual medium (cf. Robertson 2004), the scheme sketched above could be applied to other forms of representation applied to surfaces and loosely termed 'art' (cf. Perego, this volume); indeed, in many ways, writing is a particular form of representation. Like all forms of representation, its appreciation is not limited to the visual dimension: it may involve, even require (as in Braille) touch, or movement, and may, directly or by association (e.g. the text applied to consumption vessels in $18^{\text {th }}$-century Cambridge [Cessford, this volume], or classical Greece [Johnston, this volume]), instil bodily experiences of taste or smell. Denise Schmandt-Besserat (2007) has also suggested that writing and art in early Mesopotamia 'co-evolved', with the formatting and layout of writing affecting that of other visual media. It is no accident that theorists of writing from antiquity to the $20^{\text {th }}$ century saw its origin in pictures (e.g. Evans 1908; Gelb 1963; Tylor 1865: 83-106; Warburton 1765, Book IV). The same idea drove the interpretations of Egyptian hieroglyphs by Horapollo (e.g. Cory 1840) and arguably delayed the decipherment of Maya writing by over a century after Abbé Brasseur de Bourbourg's publication of Bishop Diego de Landa's account of the Maya 'alphabet' (Brasseur de Bourbourg 1864; cf. Coe 1992: 99-106).

The above considerations are appropriate to a volume on writing as 'material practice', but definitions of writing as a technology often emphasise the content of writing systems: how they work as systems, rather than their material manifestations. Powell (2009: 13), for example, defines writing - simply and concisely — as "a system of markings with a conventional reference that communicates information". We might add at the end of this definition "through time and (potentially) space"; writing removes the need for a reader to "be there'. For Powell there is no necessary link between writing and the representation of speech, a point also made by Boone (2004: 313), who defines it as "conventional, permanent, visual marks to communicate relatively specific ideas", also illustrating other "semasiographic representation systems", such as music notation, dance notation, algebra, and chemical formulae (Boone 2004: 317-335; cf. also Boone and Mignolo 1994).

Others insist on a systematic link to spoken language for a representational system to qualify as 'writing. Robertson, for example, maintains that "writing is truly writing when it systematically represents speech" (Robertson 2004: 20). This is slightly ironic, since Robertson invokes Peirceian semiotics to explain how writing can work as a representational system and Peirce was attempting to develop a much broader, inclusive understanding of how signs work (Robertson 2004: 18-19). As Powell (2009: 18) points out, such definitions echo de Saussure (1983 [1992]: 24): “[a] language and its written form constitute two separate systems of signs. The sole reason for the existence of the latter is to represent the former". Definitions that insist on writing's systematic relationship with speech break down at the khipu (Salomon, this volume), Mixtec pictorial codices (e.g. Boone 2004) or even early Sumerian 'numerical' and 'numerico-ideographic' tablets (e.g. Cooper 2004: 75-76, figs 4.4-4.5). Systems that are deeply implicated with images, like the Egyptian (cf. Baines 1989), Mayan (cf. Jackson, this volume), or Cretan Hieroglyphic (cf. Flouda; Whittaker, both this volume), also challenge definitions that limit writing to the representation of spoken language. Equally, not all writing is for reading by human eyes (e.g. certain inscriptions in Egyptian tombs or Greco-Roman curse tablets), nor strictly representative of human language (e.g. magic spells of the 'abracadabra' type).

Although we might not wish to limit a definition of writing to that of notating speech, most of the papers in this collection treat writing systems with precisely this limitation. At the other extreme, we might wish to constrain a broader definition, so as to avoid the possibility that any visual marks can constitute a writing system. There is a risk in doing so, however, because it presumably sets writing systems, however broadly defined, apart from other representational or mnemonic practices (cf. Gosden 2008, for example), equally material in basis. We may wish to keep in mind the possibility that writing, in some cultures, was one of a number of elite material practices that demanded a broader cultural, rather than a narrow linguistic literacy (cf. Perego, this volume). 
In the case of writing, the term 'conventional' is critical. Even khipu had conventions, as does musical notation, for example, and texting, as used on mobile phones (cf. Crystal 2008). Among other factors, it is convention that constrains the spread of a particular script beyond its use community (cf. Kidd, this volume, for an example of the strong link between script and language in Ptolemaic Egypt); for it to do so, the 'convention' must change (as it did, for example, when Greek-speakers adapted the Phoenician system to record their language). Extensions of script use across linguistic boundaries are much easier in the case of a script with a limited number of signs (especially an alphabet), although they are possible where prestigious and/or specialised literacy existed, as in the cultural inertia that kept Sumero-Akkadian cuneiform in use into the $1^{\text {st }}$ century вС (е.g. Black 2008; Brown 2008) to record structurally different languages (Sumerian versus Akkadian, Babylonian, Assyrian versus Hittite versus Old Persian) through both time and space (from Mesopotamia to both east and west, where it ran into the even more tenacious Egyptian tradition [e.g. Stadler 2008]). It is perhaps significant that both were replaced by alphabetic scripts: Aramaic, Greek, and Coptic.

Resistance to destabilisation through changing the 'convention' represents one reason why, in a multi-ethnic, multi-lingual, multi-scriptural area like the Levantine coastal region (cf. Sparks, this volume), at the interface between Egyptian and cuneiform systems, new 'simplified' written notations (proto-Canaanite; alphabetic Ugaritic cuneiform) emerged in response to, rather than as an adaptation of any one system; something similar might be implied by the Aegean syllabic scripts that arose on the margins of literate communities of the eastern Mediterranean (cf. Finlayson; Flouda; Tomas; Whittaker, all this volume).

\section{Before Writing}

Studies of writing as a social practice often emphasise its social context rather than content, especially in relation to its origins. For Goody, Ong, Havelock and others, writing (especially alphabetic writing) transformed society (e.g. Goody and Watt 1968; Havelock 1986; Ong 1982). In contrast to early accounts of the origins of writing that emphasised form (pictures to signs), contextual studies into the origins of writing emphasise the function that early writing fulfilled within a given society. Such studies are often 'teleological' in their conclusions - writing arose as an 'imperfect' form, 'incomplete' in relation to its later manifestations. Perhaps most familiar here is the Egyptian hieroglyphic system, whose origins are often sought in late Predynastic funerary contexts, notably that of Tomb U-j at Abydos (e.g. Dreyer 1998; see also Baines 2004). Rather than seeing the tiny labels or pots with large painted signs as the first intimations of greater 'things to come' in the fully-fledged hieroglyphic system, Piquette (2007) and others prefer to see these as part of a late $4^{\text {th }}$-millennium BC context of material practice (see also Piquette, this volume; 2008). A similar argument can be made for the earliest clay 'documents' in Sumer and, perhaps, for the earliest Aegean script use as part of a set of elite practices of display, rather than the first, imperfect steps towards a means of administrative control (cf. Bennet 2008: 5-6; Flouda, this volume; Schoep 2006: 44-48). In most cases, so the argument goes, the basic need was to deal with the amount and complexity of data to be recorded. Postgate, Wang and Wilkinson (1995), for example, argued that writing always occurs because of a need to record economic data and that the different forms it took are products of taphonomic processes that differentially preserve certain materials (cf. also Pye, this volume). Houston perceptively points out, however, that the "materiality of script differed by cultural setting" (Houston 2004: 350, his emphasis). It is difficult to imagine, for example, that we are missing extensive collections of clay documents from late PreDynastic Egypt or masses of perishable papyrus texts from later $4^{\text {th }}$-millennium BC Mesopotamia.

Denise Schmandt-Besserat (1996) famously derived writing from accounting practices already millennia old by the time the first numerical tablets were produced in Southern Iraq and Iran, 
the system only subsequently being enriched by the development of signs with phonetic values (cf. also Cooper 2004). Her argument emphasises that function and content are not necessarily co-extensive. A system (like the khipu, or her early tokens, for example) responded to a need to record and organise information, one of a number of material practices, while a phonetic element was introduced to make clear elements that could more effectively be realised through language, such as the names of institutions, divinities or individuals. Postgate (1994: 51-70) points out that cuneiform writing took centuries to acquire the range of uses that we now regard as de rigueur for any self-respecting writing system. Here a distinction between mechanics and content is important: the late $4^{\text {th }}$-millennium $\mathrm{BC}$ recording system elucidated by Schmandt-Besserat and others did not contain within it the germs of the Epic of Gilgamesh. More recently, the printing press, derived from the technologies of wine production (the screw press) and sealing / stamping in the $16^{\text {th }}$ century, defines the way we view text on screen using radically different technologies.

Emphasis on origins is important in another sense, in that writing - in the narrow sense - was not 'invented' each time it appeared; there were a limited number of original 'inventions': Egypt and Mesopotamia, although many see them as linked (e.g. Postgate 1994: 56), China and Central America. From these origins, it then spread, in the case of the Old World both to east and west, although not always as fully-formed systems (given the inertia of convention), but sometimes as the 'idea' of writing. The latter point implies a knowledge of the principles of a system and its social role. Is the invention of writing a one-way process, like the adoption of agriculture or urbanism? Systems can be lost (cf. Baines et al. 2008), but more often through replacement (most spectacularly evident in the spread of systems based ultimately on the Phoenician alphabet through much of the Old World). A particularly striking example is the replacement in the early 1920s of the Ottoman script by its western cousin, the Roman alphabet, as part of Kemal Atatürk's westernisation programme for the newly-formed Republic of Turkey (e.g. Lewis 1999: 27-39). A counter example to replacement is, of course, the loss of the syllabic Linear B script in the Aegean, unlike in Cyprus, where a syllabic script lived on alongside the novel alphabet. This example is a salutary reminder that social forces can outweigh material practices; in the Aegean it is most likely that oral practices lived on, while written died out.

\section{After Writing?}

If the invention or adoption of writing is a 'point of no return', like agriculture or urbanism, is a time 'after writing' conceivable? The chaîne opératoire for the production of this particular text sketched at its beginning worked until the late $19^{\text {th }}$ century, when sound recording became possible in a recognisable form for the first time (Gelatt 1977: 17-82; Milner 2009: 29-49); in the early $21^{\text {st }}$ century it is now possible to make sound permanent. Just as the introduction of the alphabet has been implicated in the transformation of 'Homeric' oral poetry (e.g. Powell 1991), so has the introduction of recording machinery to record not just the words, but the very sound of Yugoslav bards (even their visual performance: see the CD insert to Lord 2000). The 'permanence' of the modern world, however, is digital permanence (as Pye, this volume, reminds us), because all data - visual (including writing and image) and aural - are encoded in the same manner, using 0 s and $1 \mathrm{~s}$, the only limitations being the amount of physical storage available and the resolution at which sound and image can be sampled at 'recording' and later (dis)played. Convergence is the key word: not only are all these media encoded in the same raw material, but our devices for recording and playing back are identical too: it is possible to use your digital tablet to write, capture images and sounds, even to paint (e.g. Grant 2010). This does seem to represent a Gutenberg moment, although it will take some time for future generations to appreciate it - just as it has taken us millennia to be in a position to appreciate writing in some of the many diverse material manifestations, themselves implicated in particular historical circumstances, explored in 

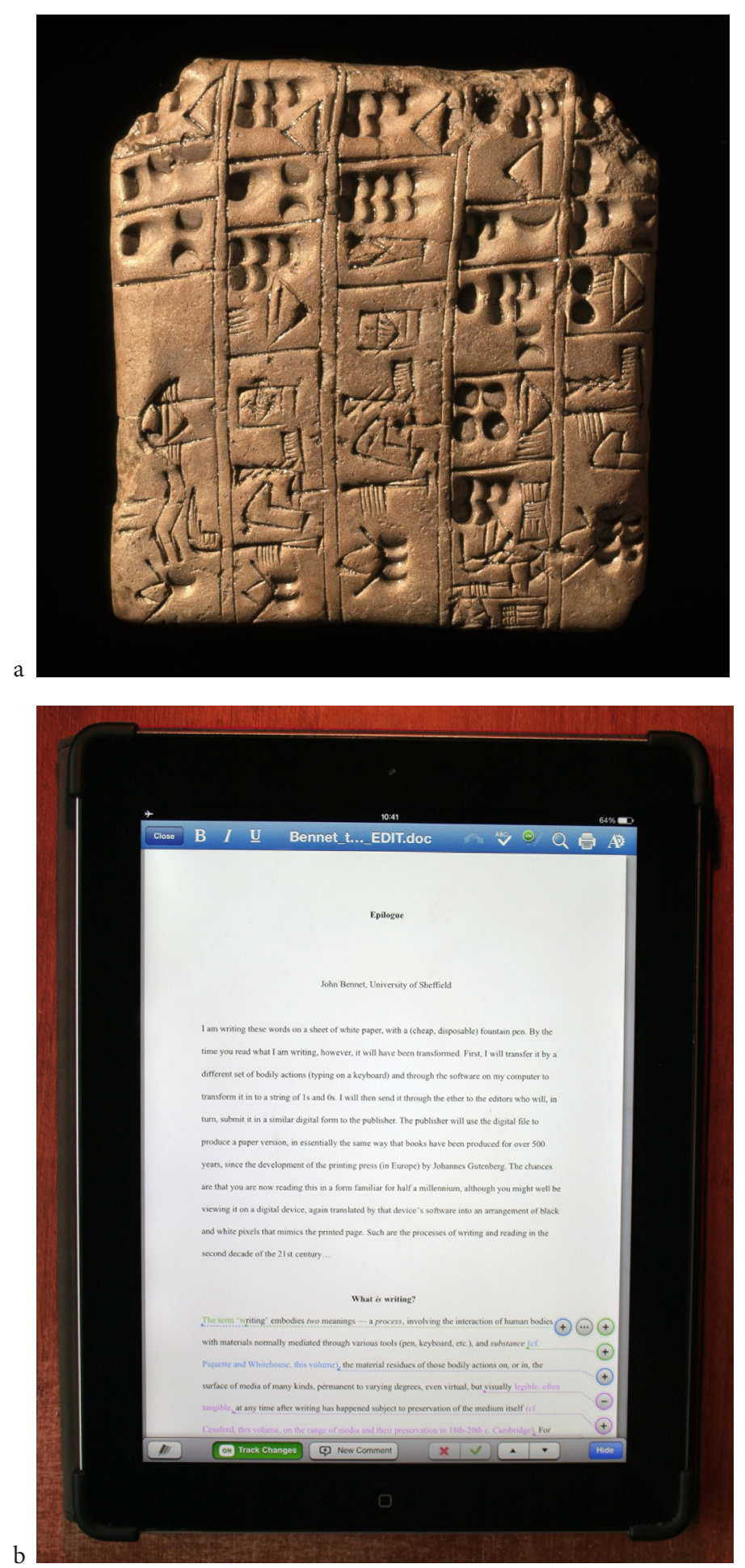

Figure 2: a) Stylus impressed clay tablet from Jemdet Nasr, dated to the Uruk III period (c.3200$3000 \mathrm{BC}) .8 .1 \mathrm{~cm} \times 7.7 \mathrm{~cm}$. BM 116730. (c) Trustees of the British Museum; b) John Bennet's Apple iPad. Author's photograph. 
this stimulating volume. It is perhaps ironic that modern terminology gives us the appearance of coming full-circle (Figure 2a-b): from early cuneiform tablets to $21^{\text {st }}$-century 'tablets'?

\section{Acknowledgements}

I am most grateful to the editors not only for the invitation to participate in the conference where these papers were originally presented, but also for their input to this contribution. John Moreland also provided characteristically perceptive and valuable comments at a late stage, despite having many other things to do.

\section{References}

Baines, J. 1989. Communication and Display: The integration of early Egyptian art and writing. Antiquity 63: 471-482.

Baines, J. 2004. The Earliest Egyptian Writing: Development, context, purpose. In Houston, S. D. (ed.), The First Writing: Script invention as history and process. Cambridge: Cambridge University Press, 150-189.

Baines, J., Bennet, J. and Houston, S. D. (eds) 2008. The Disappearance of Writing Systems: Perspectives on literacy and communication. London: Equinox.

Bennet, J. 2008. Now You See It; Now You Don't! The disappearance of the Linear A script on Crete. In Baines, J., Bennet, J. and Houston, S. D. (eds), The Disappearance of Writing Systems: Perspectives on literacy and communication. London: Equinox, 1-29.

Black, J. 2008. The Obsolescence and Demise of Cuneiform Writing in Elam. In Baines, J., Bennet, J. and Houston, S. D. (eds), The Disappearance of Writing Systems: Perspectives on literacy and communication. London: Equinox, 45-72.

Boone, E. H. 2004. Beyond Writing. In Houston, S. D. (ed.), The First Writing: Script invention as history and process. Cambridge: Cambridge University Press, 313-348.

Boone, E. H. and Mignolo, W. D. (eds) 1994. Writing Without Words: Alternative literacies in Mesoamerica and the Andes. Durham, NC: Duke University Press.

Brasseur de Bourbourg, É.-C. 1864. Relation des choses de Yucatan de Diego de Landa. Paris: Arthus Bertrand.

Brown, D. 2008. Increasingly Redundant: The growing obsolescence of the cuneiform script in Babylonia from 539 вс. In Baines, J., Bennet, J., and Houston, S. D. (eds), The Disappearance of Writing Systems: Perspectives on literacy and communication. London: Equinox, 73-101.

Coe, M. D. 1992. Breaking the Maya Code. London: Thames and Hudson.

Coe, M. D. and Kerr, J. 1997. The Art of the Maya Scribe. London: Thames and Hudson.

Cooper, J. S. 2004. Babylonian Beginnings: The origin of the cuneiform writing system in comparative perspective. In Houston, S. D. (ed.), The First Writing: Script invention as history and process. Cambridge: Cambridge University Press, 71-99.

Cory, A. T. 1840. The Hieroglyphics of Horapollo Nilous. London: William Pickering.

Crystal, D. 2008. Txtng: The Gr8 Db8. Oxford: Oxford University Press.

Dehaene, S. 2009. Reading in the Brain: The new science of how we read. London: Penguin.

Dreyer, G. 1998. Umm el-Qaab I: Das prädynastische Königsgrab U-j und seine frühen Schriftzeugnisse. Mainz am Rhein: Philipp von Zabern.

Evans, A. J. 1908. The European Diffusion of Primitive Pictography and its Bearing on the Origin of Script. In Marett, R. R. (ed.), Anthropology and the Classics: Six lectures delivered before the University of Oxford. Oxford: Clarendon Press, 9-43.

Gelatt, R. 1977. The Fabulous Phonograph, 1877-1977. London: Cassell. 
Gelb, I. J. 1963. A Study of Writing. Chicago: University of Chicago Press.

Goody, J. and Watt, I. 1968. The Consequences of Literacy. In Goody, J. (ed.), Literacy in Traditional Societies. Cambridge: Cambridge University Press, 27-68.

Gosden, C. 2008. History Without Text. In Baines, J., Bennet, J. and Houston, S. D. (eds), The Disappearance of Writing Systems: Perspectives on literacy and communication. London: Equinox, 335-346.

Grant, C. 2010. David Hockney's Instant iPad Art. http://www.bbc.co.uk/news/technology-11666162 [accessed 17 October 2013].

Havelock, E. A. 1986. The Muse Learns to Write: Reflections on orality and literacy from antiquity to the present. London: Yale University Press.

Houston, S. D. (ed.) 2004. The First Writing: Script invention as history and process. Cambridge: Cambridge University Press.

Ingold, T. 2007. Lines: A brief history. London: Routledge.

Lewis, G. 1999. The Turkish Language Reform: A catastrophic success. Oxford: Oxford University Press.

Lord, A. B. 2000. The Singer of Tales. Cambridge, MA: Harvard University Press.

Milner, G. 2009. Perfecting Sound Forever: The story of recorded music. London: Granta.

Ong, W. J. 1982. Orality and Literacy: The technologizing of the word. London: Methuen. DOI: http://dx.doi.org/10.4324/9780203328064

Piquette, K. E. 2007. Writing, 'Art' and Society: A contextual archaeology of the inscribed labels of Late Predynastic-Early Dynastic Egypt. Unpublished PhD dissertation, University College London.

Piquette, K. E. 2008. Re-materialising Script and Image. In Gashe, V. and Finch, J. (eds), Current Research in Egyptology 2008: Proceedings of the ninth annual symposium, which took place at the KNH Centre for Biomedical Egyptology, University of Manchester, January 2008. Bolton: Rutherford Press, 89-107.

Postgate, J. N. 1994. Early Mesopotamia: Society and economy at the dawn of history. London: Routledge.

Postgate, J. N., Wang, T. and Wilkinson, T. 1995. The Evidence for Early Writing: Utilitarian or ceremonial? Antiquity 69: 459-480.

Powell, B. B. 1991. Homer and the Origin of the Greek Alphabet. Cambridge: Cambridge University Press. DOI: http://dx.doi.org/10.1017/CBO9780511552700

Powell, B. B. 2009. Writing: Theory and history of the technology of civilization. Oxford: Wiley-Blackwell.

Robertson, J. S. 2004. The Possibility and Actuality of Writing. In Houston, S. D. (ed.), The First Writing: Script invention as history and process. Cambridge: Cambridge University Press, 16-38.

Saussure, F. de 1983 [1922]. Course in General Linguistics (trans. R. Harris). London: Duckworth.

Schmandt-Besserat, D. 1996. How Writing Came About. Austin, TX: University of Texas Press.

Schmandt-Besserat, D. 2007. When Writing Met Art: From symbol to story. Austin, TX: University of Texas Press.

Schoep, I. 2006. Looking Beyond the First Palaces: Elites and the agency of power in EM IIIMM II Crete. American Journal of Archaeology 110(1): 37-64. DOI: http://dx.doi.org/10.3764/ aja.110.1.37

Stadler, M. A. 2008. On the Demise of Egyptian Writing: Working with a problematic source basis. In Baines, J., Bennet, J. and Houston, S. D. (eds), The Disappearance of Writing Systems: Perspectives on literacy and communication. London: Equinox, 157-181.

Tylor, E. B. 1865. Researches into the Early History of Mankind and the Development of Civilization. London: John Murray.

Warburton, W. 1765. The Divine Legation of Moses Demonstrated, in Nine Books, Volume III (4 ${ }^{\text {th }}$ edition, corrected and enlarged). London: A. Millar and J. and R. Tonson. 